\title{
Emergent tracheostomy during the pandemic of COVID-19: Slovenian National Recommendations
}

\author{
Robert Šifrer ${ }^{1,2}$ (1) Jure Urbančič ${ }^{1,2} \cdot$ Cesare Piazza $^{3,4} \cdot$ Stijn van Weert ${ }^{5} \cdot$ Francisco García-Purriños $^{6}$. \\ Janez Benedik ${ }^{2,7} \cdot$ Ivana Tancer $^{1} \cdot$ Aleksandar Aničin ${ }^{1,2}$
}

Received: 13 April 2020 / Accepted: 21 August 2020 / Published online: 5 September 2020

(c) Springer-Verlag GmbH Germany, part of Springer Nature 2020

\begin{abstract}
Purpose Emergent tracheostomy under local anaesthesia is a reliable method of airway management when orotracheal intubation is not possible. COVID-19 is spread through aerosol making the emergent tracheostomy a high-risk procedure for surgeons. The surgical establishment of the air conduit in emergency scenarios must be adjusted for safety reasons.

Methods To establish the Slovenian National Guidelines for airway management in cannot intubate—cannot ventilate situations in COVID-19 positive patients.

Results Good communication and coordination between surgeon and anaesthesiologist is absolutely necessary. Deep general anaesthesia, full muscle relaxation and adequate preoxygenation without intubation are initial steps. The surgical cricothyrotomy is performed quickly, the thin orotracheal tube is inserted, the cuff is inflated and ventilation begins. Following patient stabilisation, the conversion to the tracheostomy is undertaken with the following features: skin infiltration with vasoconstrictor, a vertical incision, avoidance of electrical devices in favour of classical manners of haemostasis, the advancement of the tube towards the carina, performing the tracheal window in complete apnoea following adequate oxygenation, the insertion of non-fenestrated canulla attached to a heat and moisture exchanger, the fixation of canulla with stitches and tapes, and the cricothyrotomy entrance closure. Appropriate safety equipment is equally important.

Conclusion The goal of the guidelines is to make the procedure safer for medical teams, without harming the patients. Further improvements of the guidelines will surely appear as COVID-19 is a new entity and there is not yet much experience in handling it.
\end{abstract}

Keywords Cannot intubate—cannot ventilate situation · COVID-19 · Cricothyrotomy · Tracheostomy · General anaesthesia

Robert Šifrer

robert_sifrer@hotmail.com

1 University Department of Otorhinolaryngology and Cervicofacial Surgery, University Medical Centre Ljubljana, Zaloška 2, 1000 Ljubljana, Slovenia

2 Faculty of Medicine, University of Ljubljana, Vrazov trg 2, 1104 Ljubljana, Slovenia

3 Department of Otorhinolaryngology, Maxillofacial and Thyroid Surgery, National Cancer Institute of Milan, Via Giacomo Venezian 1, Milan, Italy

4 Department of Oncology and Oncohematology, University of Milan, Via Festa del Perdono 7, Milan, Italy
5 Department of Otolaryngology - Head and Neck Surgery, Amsterdam UMC, Locatie VUmc, De Boelelaan 1117, 1081 HV Amsterdam, The Netherlands

6 Servicio de Otorrinolaringología, Hospital Universitario Los Arcos del Mar Menor, Paraje Torre Octavio 54, 30739 Pozo Aledo, Murcia, Spain

7 Department of Anaesthesiology and Surgical Intensive Therapy, University Medical Centre Ljubljana, Zaloška 2, 1000 Ljubljana, Slovenia 


\section{Introduction}

\section{Airway management of acute respiratory distress under normal conditions}

For patients with acute respiratory distress due to upper airway obstruction, the establishment of an alternative and patent air conduit is a fundamental requirement [1-3]. The first step of such a procedure relies on the precise identification of the site and degree of airway obstruction through a full clinical and endoscopic examination of the upper aero-digestive tract. Subsequently, a therapeutic plan to circumvent such an airway problem should be proposed to the patient and discussed with competent colleagues in a time-sensitive fashion.

The most common option for airway management is represented by transoral endotracheal intubation after the induction of general anaesthesia, but only if this is deemed possible, upfront, by an expert anaesthesiologist. Unfortunately, there are conditions precluding such a manoeuvre, as observed in the presence of exophytic and/or easily bleeding lesions of the oral cavity, pharynx or larynx, potentially obliterating the airway lumen. On the other hand, there may be anatomic drawbacks such as long protruding upper incisors, micrognathia/retrognathia, a prominent base of the tongue, trismus, restricted degree of neck extension, and fibrotic changes of the cervical soft tissues after previous irradiation and/or surgery for head and neck cancer. If doubts about the feasibility of orotracheal intubation exist and the airway issue is caused by trismus or a large oral-oropharyngeal or supraglottic tumour, transnasal awake fiberoptic intubation (under local/topical anaesthesia) is to be considered, even though it should be reserved for experienced otorhinolaryngologists, bronchoscopists, anaesthesiologists or other medical personnel able to properly use different types of flexible fiberoptic or video endoscopes $[4,5]$.

Clinical conditions of acute dyspnoea, where the patient can neither be intubated nor ventilated, are known as "cannot intubate-cannot ventilate" situations (CICV) and represent a truly emergent clinical scenario requiring a quick and effective surgical approach to the airway. Otorhinolaryngologists are traditionally exposed to the importance of recognizing the need for urgent/emergent surgical airway management very early in their professional careers. Therefore, educational goals are set to perform tracheostomies (TS) under local anaesthesia with or without sedation within few minutes [6].

However, this procedure may be potentially associated with several problems, namely, the anxious and restless dyspnoeic and hypoxic patient, frequently not cooperating with the surgical team. Consequently, the patient can move his/her limbs unexpectedly, impeding the adequate and normal course of the surgical procedure itself. Furthermore, the opening of the trachea per se usually causes a cough with the propulsion of mucus and blood towards the faces of the surgeon and the assistants. In other words, the generation of a large quantity of aerosol is highly probable during emergent TS under local anaesthesia [7].

\section{Coronavirus disease 2019}

In December 2019, a new infectious disease emerged in the city of Wuhan in the Hubei province of China. The pandemic, called COronaVIrus Disease 2019 (COVID-19), is caused by SARS-CoV-2, a Betacoronavirus sharing approximately $80 \%$ of its phenotype with the SARS-CoV, already sadly famous in the Far East for having caused a large epidemic in 2003. COVID-19 rapidly spread all over the world beyond anyone's expectations [8]. Regarding the European Union, it was officially diagnosed first in the Lombardy region, Northern Italy, on February 21, 2020, while the first reported case in Slovenia dates back to March 4, and the number of new cases has been rising ever since. According to the John Hopkins University Map, on June 26, there were 1558 total cases of confirmed COVID-19 patients and, altogether, 109 related deaths in Slovenia (2 million inhabitants). The further rise of the infection can be, unfortunately, expected.

The inter-human transmission of COVID-19 (born as a zoonosis) occurs through droplets and aerosol spread containing SARS-CoV-2 particles. The droplets may stay airborne for a few hours and travel a short distance before landing onto surfaces [9]. These potentially highly contagious droplets are produced during coughing and sneezing and can spread quickly among the population if preventive measures are neglected. According to the ENT UK and the Royal College of Surgeons of England [7], the aerosol is also produced during medical and surgical interventions at the level of the upper aerodigestive tract, thus including TS $[10,11]$.

\section{Emergent tracheostomy issues related to COVID-19}

Emergent TS, with an unsecured airway in a conscious patient, is, for the aforementioned reasons, hazardous regarding the potential transmission of SARS-CoV-2 to surgical teams. Therefore, to ensure the maximal safety of the procedure, we decided to establish the present Slovenian National Guidelines, codifying the proper conduct to be followed in the face of emergent TS for CICV scenarios. They were set taking into account a literature review including, in particular, the British [12] and Spanish [13] Guidelines for TS as well as personal experience and communication with other colleagues from 
Slovenia and with foreign head and neck surgeons from Italy, Spain, and The Netherlands.

All patients admitted to our clinical institution are tested for COVID-19 using a nasopharyngeal smear. As long as their COVID-19 status remains unknown, patients are admitted to a specially designated wing of the building. After the confirmation of the results (potentially lasting several hours), patients are further triaged to the appropriate department or operating theatre. However, clinical emergencies intrinsically related to acute dyspnoea with severe inspiratory stridor does not allow the time to wait. In this case, patients must be considered COVID-19 positive and the ensuing steps for airway surgical establishment must be taken accordingly as delaying surgery while waiting for COVID-19 results might lead to the death of the patient $[12,14]$.

The pathological background causing CICV status was, in the pre-COVID-19 era, determined by clinical examination using one of three alternatives - an indirect (mirror) laryngoscopy or transoral rigid laryngoscopy or transnasal flexible fiberoptic laryngoscopy.

As for COVID-19, several issues must be discussed. All of the above listed diagnostic procedures, in fact, generate aerosol and may result in the transmission of the virus to the examiner. The transnasal flexible fiberoptic laryngoscopy is strongly discouraged in a COVID-19 positive setting due to the manipulation of the high-risk nasal mucosa [14-16], whereas mirror and transoral rigid endoscopic examinations frequently lead to coughing and gagging.

In this aspect, the safest and most useful diagnostic tool, also preferred in Italy, is likely a transnasal flexible fiberoptic endoscopy performed from behind. To illustrate, the surgeon stands behind the patient with both facing the same direction (towards the screen). In this manner, they observe the image of the patient's airway simultaneously. There are some indisputable advantages of endoscopy from behind in comparison to alternative diagnostic options. Firstly, the coughing and gagging very rarely occur. Secondly, the distance between the face of the surgeon and the patient's nose/mouth is maximal. Thirdly, the direction of the potential aerosol spread from the patient is favourable since, even when coughing or gagging or sneezing occurs, the patient does not disperse aerosol toward the surgeon but away from him.

Irrespective of the pros and cons, the evaluation of the airway in COVID-19 positive patients should be done according to one's individual experience and preferences as well as on a case-by-case basis. What matters is that the examination is performed properly and promptly given the mainstay of appropriate personal protective equipment (PPE).

\section{What does the literature say?}

In the literature, no article related solely to emergent TS in patients with COVID-19 has been published so far. On the other hand, numerous articles exist discussing elective TS for prolonged intubated patients, and, in the minority of them, there are only a few sentences or paragraphs dedicated to emergent TS. That having been said, emergent TS in COVID-19 patients has not been thoroughly discussed in the pertinent literature, but only briefly and superficially mentioned by certain authors.

In patients with confirmed/suspected COVID-19, some important issues must be addressed. Emergent TS as the first step under local anaesthesia in a sedated patient is, despite extensive experience, discouraged due to the high risk of potentially infectious aerosol production from the unprotected airway [7, 17-19]. As such, the risk of surgical procedures for healthcare workers should be always carefully balanced with the potential benefits for the patients $[18,20]$.

Many authors are reluctant to establish an emergent surgical airway in patients with COVID-19. To begin with, Miles suggests less invasive techniques to manage the acute airway initially, such as endotracheal intubation, intubation under video-laryngoscope or fiberoptic guidance to avoid emergent TS [17]. Similarly, Shiba, instead of emergent surgical airway procedure, advocates a laryngeal mask to secure the airway first. This can later be converted to endotracheal intubation under bronchoscopic guidance, although bronchoscopy is a well-known aerosol-generating procedure [15]. The emergent TS should, of course, be done if the intubation techniques fail [17].

Moreover, Sommer states that both awake TS and cricothyrotomy (CTT) should be considered risky and avoided whenever possible. Notably, these procedures should be considered in extenuating circumstances only [18], which the CICV situation definitely is. In an un-intubated patient, Schultz, likewise, strongly advises against TS except in absolute vital emergencies. However, should it become necessary, he recommends the injection of $5 \mathrm{~mL}$ of $5 \%$ lidocaine intratracheally to suppress the patients' cough before creating the tracheal window [19].

The fact that the vast majority of clinicians stress the importance of the safety of medical personnel through the use of PPE and the limitation in the number of caregivers during acute airway management requires no further explanation [14, 15, 17, 19-21].

Other authors are keener on performing emergent TS and give some advice on how to do it and warn of potential complications and aerosol spread. At first, according to Skoog, emergent TS should be performed as an indication (tumour, stenosis, trauma etc.) necessitates. It should be 
performed in the same way as an elective one in patients with COVID-19 but with enhanced airway precautions [22].

Secondly, with the COVID-19 pandemic, attention has been largely focused on the safety of medical and nurse teams despite the emergent situation. Therefore, Michetti and Shiba assert that neuromuscular blockade is justified before the surgical entrance of the airway and that the ventilation is held prior to CTT and until the placement of the definitive airway [15, 23]. In the event of a difficult or unsuccessful placing of the tube into the CTT opening and consequent demand for ventilation, the CTT opening should be occluded with one's finger to prevent both air and aerosol leakage and then ventilation by the bag-valve mask can commence [23].

Furthermore, as the first step of acute airway management, Shiba promotes less invasive methods of airway establishment. However, should the situation deteriorate to the point that surgical airway entrance is required, CTT is suggested followed by the conversion to TS [15]. On the contrary, in the case of an airway emergency, Heyd immediately begins with TS. To execute the procedure safely, he carefully follows the same guidelines as one would for elective TS in patients with COVID-19 [20].

Since there is no effective treatment nor vaccine for COVID-19 yet, and SARS-CoV-2 is known to spread extremely rapidly, the emphasis is placed on preventive measures. TS under local anaesthesia as the initial step of surgical airway management in an emergency setting is disadvised and should be, from our point of view, avoided.

\section{Emergent establishment of the surgical airway in COVID-19 patients}

Instead, we herein propose to proceed with the induction of general anaesthesia with the previously closed circle preoxygenation (completely sealed face mask, with $80 \%$ oxygen, for at least $3 \mathrm{~min}$ ), without orotracheal intubation [13]. Patients should receive complete muscle relaxation (controlled by peripheral nerve stimulator, train of four value zero) and deep general anaesthesia [Bispectral index (BIS) value 30-40] throughout the whole procedure from this point on $[24,25]$.

Secondly, the establishment of a surgical airway by (rapid four-step technique, RFST) CTT is advised and should be executed as quickly as possible [26] as soon as the patient is in complete apnoea. A thin (size 5.5 or less) orotracheal tube is then inserted through the opening of the cricothyroid membrane down in the distal airway. Only after the cuff is appropriately inflated will the anaesthesiologist begin to ventilate the patient.
While the patient is being stabilized by the anaesthesiologist, the surgical team must prepare for the immediate conversion of the CTT into a formal TS, in order to avoid the potential issues related to the long-lasting presence of a tracheostomic cannula within a CTT (cannula dislodgement, inappropriate cannula size, persistent cough, cricoid chondritis, and subglottic stenosis). The skin is therefore infiltrated with local anaesthetic and vasoconstrictor agents [27], and incised vertically between the cricoid and the sternum. The anterior tracheal wall is surgically exposed and haemostasis is achieved without using electrocautery or other plume-generating devices.

When the surgeon is ready to open the trachea, the anaesthesiologist should confirm deep anaesthesia, complete muscle relaxation, and full oxygenation [12]. It is of the utmost importance that the anaesthesiologist stops ventilating the patient at this point and allows time for passive expiration with an open adjustable pressure-limiting (APL) valve.

Then, with the patient still in apnoea, the tube should be advanced distally so that the position of the cuff is located inferiorly to the proposed tracheal window. The surgical assistant or the scrub nurse maintains the tube position and, providing the oxygenation is still adequate, the tracheal window is created, being careful not to inadvertently cut the cuff. The window should be of sufficient size and its margins smooth to prevent potential injury to the cuff.

Once the tracheal lumen is cleared of mucus, the lateral sides of the tracheal window are sutured to the previously mobilized neck skin with two stitches on each side. As the adult trachea is usually much wider than the tube in the trachea, there should be enough space to place the sutures.

After the sutures have been properly tied, the tube is deflated and slowly retracted cranially but not entirely removed from the cricothyroid space. A non-fenestrated cuffed tracheal cannula attached to an antiviral heat and moisture exchanger (HME) filter is inserted (without the plastic guide) and the cuff is inflated. The cannula with its HME is connected to the ventilator and the anaesthesiologist resumes the ventilation of the patient.

The neck of the patient is then released from the hyperextended position into a slight flexion, imitating their normal position in the intensive care unit or the hospital ward. Following the confirmation of the good position of the cannula, the tube is completely removed from the cricothyroid space and discarded. The cannula is secured with stitches to the skin and the tapes around the neck while the cricothyroid opening is surgically repaired with absorbable, extramucosal 2.0 sutures.

\section{Safety equipment}

Hood powered air-purifying respirator (PAPR) systems should be used by operating teams when performing surgical procedures on COVID-19 positive patients. TS is essentially 
one of the surgical procedures where aerosols are most prone to occur [10]. All members of the team should use disposable scrubs, water-resistant protective gowns and, over them, sterile surgical gowns. We also propose a similar two-layer solution for gloves with, first, a pair of thick nitrile gloves and, over those, sterile surgical gloves. Disposable socks and shoes must cover and protect the surgeons' feet. With all of these precautions, obviously, putting the PPE on and off (i.e., donning and doffing) are quite cumbersome. Moreover, some peculiar problems such as diminished feeling in the fingers, overheating and the constant disturbing noise of PAPR may be experienced during the procedure.

However, when the patients' situation is extremely urgent (apnoea, oxygen saturation lower than $80 \%$, impossible ventilation through the mask), it is not wise to waste $20 \mathrm{~min}$ dressing up. In such cases, a filtering face piece (FFP) $2 / 3$ mask or face mask with high-efficiency particulate air (HEPA) filter (non-PAPR), long visor or safety goggles, preferably with a tight fit, and any surgical gown is preferred. It might not protect the members of the team for a prolonged period, but it is very likely enough to secure the surgical airway by CTT.

It is also imperative to appropriately train the team for doffing and donning $[9,10]$ since, for any suboptimal use of the PPE, the real possibility of hazard exposure greatly rises. When team members do not use water-resistant protective gowns, douching is recommended.

\section{Comments}

These guidelines were fuelled by a pre-emptive discussion at our Department on how to better prepare for the expected surge of COVID-19 patients and are based on the British [12] and Spanish [13] Guidelines, as well as on a series of discussions with several specialists from Italy, Spain, The Netherlands, and Slovenia. This was aimed at balancing the scarce data currently present in the literature. Furthermore, our experience in elective TS for confirmed COVID-19 patients was taken into account as well. We herein explain potentially disputable issues concerning such guidelines.

\section{Location}

The optimal location for surgical airway management in COVID-19 positive patients is a dedicated COVID-19 operating room [28], especially for those with anatomic constraints, e.g. severe obesity, short necks, and fibrotic changes after previous oncologic treatments impeding the identification of essential neck landmarks [23]. However, if the surgical airway required in an emergency setting does not allow sufficient time for transportation to an operating theatre, a bedside procedure should be performed at emergency clinics or any other location where the patient is presented and first evaluated [15, 19, 23]. In both cases, it is recommended that negative pressure rooms are used whenever possible [29, 30]. Although this setting would be ideal, it is not always feasible-especially in Europe where most operating theatres are at positive pressure [31]. In addition, in the case of bedside TS, suboptimal lighting, surgeon, and patient positioning should be taken into account $[11,21]$.

\section{General anaesthesia}

Open TS under local anaesthesia in a CICV scenario for patients with an unknown or positive COVID-19 status is too hazardous for the health care workers involved in the procedure. Instead, CTT is easier, safer, faster, and is associated with less bleeding [32, 33]. Therefore, we decided to promote such an alternative emergent procedure following the latest Advanced Trauma Life Support manual that recommends surgical CTT over TS for patients in need of the emergent establishment of a surgical airway [32, 33].

Again for safety reasons, we propose proceeding with CTT after putting the patient under deep general anaesthesia with full muscle relaxation and proper oxygenation, but without intubation. In our opinion, in fact, an adequate balance between a higher level of security for the surgical team due to reduced exposure to potentially hazardous aerosol and a non-significantly augmented risk for the patient during a short manoeuvre of CTT is thus achieved. The importance for both surgeon and anaesthesiologist to keep professional and fair communication throughout the entire procedure cannot be over-emphasized, since a slight misunderstanding and lack of coordination between the two can lead to significant aerosol production, without mentioning the patient's hazard. Moreover, within the framework of the herein described procedure, adequate oxygenation of the patient after CTT gives the surgeon enough time to create an adequate and stable tracheal window in apnoea, thus reducing the risk of causing undue damage to the airway.

\section{Cricothyrotomy}

There are many techniques for performing CTTs and they are generally divided into four groups. The first makes use of commercial kits based on the Seldinger guidewire technique, the second on kits not based on Seldinger techniques, the third on needle techniques, and the last on surgical techniques. In the systematic review of Langvad comparing various techniques, it was concluded that none of the above provides better results than the others, so the success rate of the CTT relies mainly on the surgeon's experience and skills [26].

The needle techniques are of no use in this situation as it has been argued that they do not lead to adequate 
oxygenation and ventilation due to the small needle calibre [26]. The arguments against the use of both Seldinger and non-Seldinger methods are the insufficient lengths of the cannulas not allowing their advancement towards the tracheal carina before the creation of the tracheal window. The consequence of this is that the cuff cannot be placed inferiorly of the planned tracheal window, which is an essential step in COVID-19 patient management.

Moreover, the CICV situation is not encountered on a daily basis, so a vast majority of clinicians lack adequate experience. What is more, CTT is always performed under stressful conditions, in suboptimal circumstances (even further deteriorated by the COVID-19 issue), and under severe time constraints [26]. Consequently, we believe that each surgeon should choose the technique(s) he is most experienced in. As already mentioned, kits are not used on a regular basis but, presumably, only once or twice in a lifetime. We, therefore, believe that no ENT surgeon is truly experienced in using such kits over cold-steel instruments such as scalpels and scissors. The CTT technique we herein suggest is the so-called RFST consisting of [34]:

1. Palpation of the cricothyroid membrane, which is a soft horizontal region below the inferior border of the thyroid and above the cricoid cartilage along the midline.

2. Horizontal incision through the skin, prelaryngeal muscles, and cricothyroid membrane entering the lumen of the larynx.

3. Traction of the arch of the cricoid cartilage with a hook downwards, or of the inferior border of the thyroid upwards.

4. Insertion of a thin cuffed endotracheal tube.

For surgical CTT, the following instruments are also optional: bougie [35], CTT scissors [36], or the Bair claw device [37]. Again, it is a matter of personal preference and skill.

\section{Conversion to tracheostomy}

Traditionally, CTT was converted to formal TS within $72 \mathrm{~h}[33,38]$. This statement was based upon the historical assumption that CTT is associated with an extremely high risk of subglottic stenosis [39]. It was later argued that this is not necessarily the case [40]. Moreover, there seems to be no significant difference in the complication rates of CTT and TS [41], while the incidence of late complications might be even higher with TS compared to CTT ( $25.1 \%$ vs. $13.6 \%)$ [33]. Various studies report the rate of conversion for CTT as ranging from $0-100 \%$ [38], without differences in terms of long-term benefits between the conversion and permanence of CTT [42, 43]. However, considering the lack of experience of personnel in the postoperative care of CTT in comparison to TS in our wards as well as the higher risk of CTT cannula dislodgement and/or occlusion, in our opinion, conversion to a formal TS is strongly suggested. Moreover, to minimize the exposure of the attending personnel to the risk of a second procedure, we advise it to be done during the same session, just after CTT, as previously described.

As a matter of fact, the potential number of subglottic and/or tracheal stenoses due to the higher number of airway procedures (including prolonged orotracheal intubations, TS, and CTT) consequent to the COVID-19 pandemic, cannot be precisely sized as such but will be, inevitably, high [44]. In this sense, an accurate closure of the CTT and appropriate opening of the trachea may help to limit such adverse future events.

\section{Tracheostomy}

The vertical incision of the skin for TS offers two advantages. First, the edges of the surgical wound in the extended neck passively retract laterally, improving the visibility of the deeper tissues. Secondly, the lateral borders of the surgical wound are parallel to the lateral sides of the tracheal window which facilitates the stitching of the trachea to the skin. For the same reason, the undermined skin enables an easier approximation of the skin to the tracheal window. On the flip side, the disadvantage of the vertical skin incision is its aesthetically less acceptable scar following decannulation.

The tracheal wall is exposed a bit more (as opposed to the TS under normal circumstances) to allow more space for the surgeon to create a safe tracheal window. The rationale is the time constraint during apnoea when the trachea is already open. The edges of the window should be smooth and without spikes to avoid the potential perforation of the cuff during surgery or later in the ward. This situation would necessitate the unplanned replacement of the cannula at the bedside, again with the potential for contagious aerosol spread. To prevent the exposure of teams in the event of coughing during its insertion in the operatory room, the cannula is connected to an antiviral HME filter beforehand. In this setting, the introduction is performed without the plastic guide, making it a bit more demanding, but safer for the personnel.

It is of great importance to reiterate that haemostasis by diathermy and other devices producing plumes is strongly disadvised in patients with COVID-19. The greatest risk for aerosol spread during the implementation of such manoeuvres is after the opening of the trachea due to the potential release of droplets.

In the case of a thoroughly secured airway or before surgically entering the airway, the infectious droplets do not have direct access to the surgical field. Notwithstanding, the risk of transmission might not be zero, as a low level of viremia has been detected in 1-15\% of symptomatic patients 
with COVID-19 [45-47]. Until more is established about the frequency and the levels of viral RNA in the blood of affected patients, all surgeries should be executed as if the spread is theoretically possible also via blood transmission. Apart from banning electrical devices and promoting classic haemostasis with surgical ties or chemocautery, on the other hand, infiltration of the skin with local anaesthetic and vasoconstrictor agents is also suggested to reduce potential bleeding [27].

The inadvertent removal or spontaneous dislodgement of the cannula from the trachea is a well-known inconvenience in both ENT and intensive care wards. The resulting acute respiratory distress demands rapid reinsertion of the cannula. Owing to the high-risk of SARS-CoV-2 transmission during tracheal cannula replacement, it would be wise to prevent the falling-out of the cannula ensuring that, when needed, the eventual reinsertion is as simple as possible. These are the reasons for suggesting, first, to suture the tracheal wall to the skin and, second, to suture the cannula to the skin.

\section{Conclusions}

The current national guidelines were essentially aimed at making the emergent airway establishment as safe as possible for surgical teams in the era of the COVID-19 pandemic. Currently, there is not much experience worldwide regarding COVID-19 as it is a quite new pathologic entity; therefore, extreme caution is mandatory. The reader is therefore advised to follow these precautionary guidelines and consider each particular step in advance. In this way, and particularly after dealing with CICV COVID-19 positive patients in the surgical theatres of different countries, new ideas, later refinements, and future improvements of the guidelines will definitively appear.

Funding No funding was received.

\section{Compliance with ethical standards}

Conflict of interest The authors declare that they have no conflict of interest.

Ethics approval It was not required.

\section{References}

1. Berlac P, Hyldmo PK, Kongstad P, Kurola J, Nakstad AR, Sandberg M (2008) Pre-hospital airway management: guidelines from a task force from the scandinavian society for anaesthesiology and intensive care medicine. Acta Anaesthesiol Scand 52(7):897-907
2. Henderson JJ, Popat MT, Latto IP, Pearce AC, Society DA (2004) Difficult Airway Society guidelines for management of the unanticipated difficult intubation. Anaesthesia 59(7):675-694

3. Apfelbaum JL, Hagberg CA, Caplan RA, Connis RT, Nickinovich DG, Benumof JL et al (2013) Practice guidelines for management of the difficult airway: an updated report by the American Society of anesthesiologists task force on management of the difficult airway. Anesthesiology 118(2):251-270

4. Kim H, So E, Karm MH, Kim HJ, Seo KS (2017) Learning fiberoptic intubation for awake nasotracheal intubation. J Dent Anesth Pain Med 17(4):297-305. https://doi.org/10.17245/jdapm .2017.17.4.297 (Epub 2017 Dec 28)

5. Cabrini L, Baiardo Redaelli M, Ball L, Filippini M, Fominskiy E, Pintaudi M, Putzu A, Votta CD, Sorbello M, Antonelli M, Landoni G, Pelosi P, Zangrillo A (2019) Awake fiberoptic intubation protocols in the operating room for anticipated difficult airway: a systematic review and meta-analysis of randomized controlled trials. Anesth Analg 128(5):971-980. https://doi.org/10.1213/ ANE.0000000000004087

6. European Union of medical specialists (UEMS). Logbook otorhino-laryngology-head and neck surgery (revision 2018) training programme. https://orluems.com/gestor/upload/LOGBO OK\%2520REVISED\%2520FINAL\%25202019.pdf. Accessed $10 \mathrm{Feb} 2020$

7. Philpott C, Burrows S. Aerosol-generating procedures in ENT. Legeforeningen. https://www.legeforeningen.no/contentass ets/8d2b776522c34deb8f57fa618cb07c32/aerosol-generating -procedures-in-ent_compressed.pdf (Accessed 5 Apr 2020)

8. Tomažič J. Covid-19: kaj je dobro, da ve vsak zdravnik. [cited 2020 May 10]. Available from: https://www.mf.uni-lj.si/applicatio n/files/3815/8714/7642/Covid-19_Tomazic_J_1.pdf

9. Vukkadala N, Qian ZJ, Holsinger FC, Patel ZM, Rosenthal E (2020) COVID-19 and the otolaryngologist - preliminary evidence-based review. Laryngoscope. https://doi.org/10.1002/ lary.28672 (Epub ahead of print)

10. Ti LK, Ang LS, Foong TW, Ng BSW (2020) What we do when a COVID-19 patient needs an operation: operating room preparation and guidance. Can J Anaesth. https://doi.org/10.1007/s1263 0-020-01617-4 (Epub ahead of print)

11. McGrath BA, Brenner MJ, Warrillow SJ, Pandian V, Arora A, Cameron TS, Añon JM, Hernández Martínez G, Truog RD, Block SD, Lui GCY, McDonald C, Rassekh CH, Atkins J, Qiang L, Vergez S, Dulguerov P, Zenk J, Antonelli M, Pelosi P, Walsh BK, Ward E, Shang Y, Gasparini S, Donati A, Singer M, Openshaw PJM, Tolley N, Markel H, Feller-Kopman DJ (2020) Tracheostomy in the COVID-19 era: global and multidisciplinary guidance. Lancet Respir Med 20:2213-2600. https://doi.org/10.1016/S2213 -2600(20)30230-7

12. Harrison L, Ramsden J, Winter S, Rocke J, Heward E. Tracheostomy guidance during the COVID-19 Pandemic. ENT UK. https ://www.entuk.org/tracheostomy-guidance-during-covid-19-pande mic. (Accessed 5 Apr 2020)

13. Comisión de cabeza y cuello y base de cráneo de la SEORL-CCC, Comisión Delegada SEORL-CCC (2020) Recomendaciones de la sociedad española de otorrinolaringología y cirugía de cabeza y cuello para la realización de traqueotomías en relación a pacientes infectados por coronavirus covid-19 https://seorl.net/wp-content/ uploads/2020/03/Traqueo-COVID19.pdf.pdf.pdf

14. Krajewska J, Krajewski W, Zub K, Zatoński T (2020) COVID19 in otolaryngologist practice: a review of current knowledge. Eur Arch Otorhinolaryngol 277(7):1885-1897. https://doi. org/10.1007/s00405-020-05968-y (Epub 2020 Apr 18)

15. Shiba T, Ghazizadeh S, Chhetri D, St John M, Long J (2020) Tracheostomy Considerations during the COVID-19 Pandemic. OTO Open 4(2):2473974X20922528. https://doi.org/10.1177/24739 74X20922528 (eCollection 2020 Apr-Jun) 
16. Patel ZM, Fernandez-Miranda J, Hwang PH, Nayak JV, Dodd R, Sajjadi H, Jackler RK (2020) Letter: precautions for endoscopic transnasal skull base surgery during the COVID-19 pandemic. Neurosurgery 87(1):E66-E67. https://doi.org/10.1093/neuros/ nyaa 125

17. Miles BA, Schiff B, Ganly I, Ow T, Cohen E, Genden E, Culliney B, Mehrotra B, Savona S, Wong RJ, Haigentz M, Caruana S, Givi B, Patel K, Hu K (2020) Tracheostomy during SARS-CoV-2 pandemic: recommendations from the New York Head and Neck Society. Head Neck. https://doi.org/10.1002/hed.26166 (Epub ahead of print)

18. Sommer DD, Engels PT, Weitzel EK, Khalili S, Corsten M, Tewfik MA, Fung K, Cote D, Gupta M, Sne N, Brown TFE, Paul J, Kost KM, Witterick IJ (2020) Recommendations from the CSO-HNS taskforce on performance of tracheotomy during the COVID-19 pandemic. J Otolaryngol Head Neck Surg 49(1):23. https://doi.org/10.1186/s40463-020-00414-9

19. Schultz P, Morvan JB, Fakhry N, Morinière S, Vergez S, Lacroix C, Bartier S, Barry B, Babin E, Couloigner V, Atallah I (2020) French Society of Otorhinolaryngology, Head, Neck Surgery (SFORL); French Society of Head, Neck Carcinology (SFCCF) French consensus regarding precautions during tracheostomy and post-tracheostomy care in the context of COVID-19 pandemic. Eur Ann Otorhinolaryngol Head Neck Dis. 20:1879-7296. https ://doi.org/10.1016/j.anorl.2020.04.006

20. Heyd CP, Desiato VM, Nguyen SA, O'Rourke AK, Clemmens CS, Awad MI, Worley ML, Day TA (2020) Tracheostomy protocols during COVID-19 pandemic. Head Neck. https://doi.org/10.1002/ hed.26192 (Epub ahead of print)

21. Faris C, Deben K, van Haesendonck G et al (2020) Making sense of personal protective equipment (PPE) and tracheostomy in the midst of the COVD-19 pandemic. B-ENT. https://doi.org/10.5152/ B-ENT.2020.20128 (Epub ahead of print)

22. Skoog H, Withrow K, Jeyarajan H, Greene B, Batra H, Cox D, Pierce A, Grayson JW, Carroll WR (2020) Tracheotomy in the SARS-CoV-2 pandemic. Head Neck. https://doi.org/10.1002/ hed.26214 (Epub ahead of print)

23. Michetti CP, Burlew CC, Bulger EM, Davis KA, Spain DA (2020) Critical care and acute care surgery committees of the American Association for the Surgery of trauma performing tracheostomy during the Covid-19 pandemic: guidance and recommendations from the critical care and acute care surgery committees of the American Association for the surgery of trauma. Trauma Surg Acute Care Open 5(1):e000482. https://doi.org/10.1136/tsaco -2020-000482

24. Rüsch D, Arndt C, Eberhart L, Tappert S, Nageldick D, Wulf H (2018) Bispectral index to guide induction of anesthesia: a randomized controlled study. BMC Anesthesiol 18(1):66. https://doi. org/10.1186/s12871-018-0522-8

25. Mashour GA, Avidan MS (2015) Intraoperative awareness: controversies and non-controversies. Br J Anaesth 115:i20-i26

26. Langvad S, Hyldmo PK, Nakstad AR, Vist GE, Sandberg M (2013) Emergency cricothyrotomy-a systematic review. Scand J Trauma Resusc Emerg Med 21:43. https://doi. org/10.1186/1757-7241-21-43

27. Ghali S, Knox KR, Verbesey J, Scarpidis U, Izadi K, Ganchi PA (2008) Effects of lidocaine and epinephrine on cutaneous blood flow. J Plast Reconstr Aesthetic Surg 61(10):1226-1231

28. Broderick D, Kyzas P, Sanders K, Sawyerr A, Katre C, Vassiliou L (2020) Surgical tracheostomies in Covid-19 patients: important considerations and the "5Ts" of safety. Br J Oral Maxillofac Surg. https://doi.org/10.1016/j.bjoms.2020.04.008 (Epub ahead of print)

29. Syamal M (2020) Literature-guided recommendations for otolaryngologists during the COVID-19 pandemic: a contemporary review. Laryngoscope Invest Otolaryngol 1:6. https://doi. org/10.1002/lio2.389 (Epub ahead of print)

30. Mecham JC, Thomas OJ, Pirgousis P, Janus JR (2020) Utility of tracheostomy in patients with COVID-19 and other special considerations. Laryngoscope. https://doi.org/10.1002/lary.28734 (Epub ahead of print)

31. Takhar A, Walker A, Tricklebank S, Wyncoll D, Hart N, Jacob T, Arora A, Skilbeck C, Simo R, Surda P (2020) Recommendation of a practical guideline for safe tracheostomy during the COVID-19 pandemic. Eur Arch Otorhinolaryngol. https://doi.org/10.1007/ s00405-020-05993-x (Epub ahead of print)

32. American College of Surgeons (2018) Advanced trauma life support. American College of Surgeons, Committee on Trauma, Chicago

33. DeVore EK, Redmann A, Howell R, Khosla S (2019) Best practices for emergency surgical airway: a systematic review. Laryngoscope Investig Otolaryngol 4(6):602-608. https://doi.org/10.1002/ lio2.314 (eCollection 2019 Dec)

34. Holmes JF, Panacek EA, Sakles JC, Brofeldt BT (1998) Comparison of 2 cricothyrotomy techniques: standard method versus rapid 4-step technique. Ann Emerg Med 32(4):442-446

35. Hill C, Reardon R, Joing S, Falvey D, Miner J (2010) Cricothyrotomy technique using gum elastic bougie is faster than standard technique: a study of emergency medicine residents and medical students in an animal lab. Acad Emerg Med 17(6):666-669

36. Schober P, Hegemann MC, Schwarte LA, Loer SA, Noetges P (2009) Emergency cricothyrotomy-a comparative study of different techniques in human cadavers. Resuscitation 80(2):204-209

37. Bair AE, Sakles JC (1999) A comparison of a novel cricothyrotomy device with a standard surgical cricothyrotomy technique. Acad Emerg Med 6(11):1172-1174

38. Macêdo MB, Guimarães RB, Ribeiro SM, DE Sousa KMM (2016) Emergency cricothyrotomy: temporary measure or definitive airway? A systematic review. Rev Col Bras Cir 43(6):493-499. https ://doi.org/10.1590/0100-69912016006010

39. Jackson C (1921) High Tracheotomy and other errors-The chief causes of chronic laryngeal stenosis. Surg Gynecol Obstet 32:392-398

40. Brantigan CO, Grow JB (1976) Cricothyroidotomy: elective use in respiratory problems requiring tracheotomy. $\mathrm{J}$ Thorac Cardiovasc Surg 71(1):72-81

41. François B, Clavel M, Desachy A, Puyraud S, Roustan J, Vignon $P$ (2003) Complications of tracheostomy performed in the ICU: subthyroid tracheostomy vs surgical cricothyroidotomy. Chest 123(1):151-158

42. Graham DB, Eastman AL, Aldy KN, Carroll EA, Minei JP, Brakenridge SC et al (2011) Outcomes and long term follow-up after emergent cricothyroidotomy: is routine conversion to tracheostomy necessary? Am Surg 77(12):1707-1711

43. Dillon JK, Christensen B, Fairbanks T, Jurkovich G, Moe KS (2013) The emergent surgical airway: cricothyrotomy vs. tracheotomy. Int J Oral Maxillofac Surg 42(2):204-208. https://doi. org/10.1016/j.ijom.2012.10.021 (Epub 2012 Dec 21)

44. Piazza C, Filauro M, Dikkers FG, Nouraei SAR, Sandu K, Sittel C, Amin MR, Campos G, Eckel HE, Peretti G (2020) Long-term intubation and high rate of tracheostomy in COVID-19 patients might determine an unprecedented increase of airway stenoses: a call to action from the European Laryngological Society. Eur Arch Otorhinolaryngol. https://doi.org/10.1007/s00405-020-06112-6 (Epub ahead of print)

45. Huang C, Wang Y, Li X, Ren L, Zhao J, Hu Y et al (2020) Clinical features of patients infected with 2019 novel coronavirus in Wuhan. China Lancet 395(10223):497-506

46. Young BE, Ong SWX, Kalimuddin S, Low JG, Tan SY, Loh J et al (2020) Epidemiologic features and clinical course of patients 
infected with SARS-CoV-2 in Singapore. JAMA. https://doi. org/10.1001/jama.2020.3204 (Epub ahead of print)

47. Wang W, Xu Y, Gao R, Lu R, Han K, Wu G et al (2020) Detection of SARS-CoV-2 in different types of clinical specimens. JAMA. https://doi.org/10.1001/jama.2020.3786
Publisher's Note Springer Nature remains neutral with regard to jurisdictional claims in published maps and institutional affiliations. 